doi $\underline{\text { http://dx.doi.org/10.18542/rmi.v15i24.10102 }}$

Margens: Revista Interdisciplinar | e-ISSN:1982-5374 | V. 15 | N. 24 | Jun, 2021, pp. 275-290.

\title{
EDUCAÇÃO INCLUSIVA EM TEMPOS DE PANDEMIA: DESAFIOS PARA A
} INCLUSÃO

\section{INCLUSIVE EDUCATION IN TIMES OF PANDEMICS: CHALLENGES FOR INCLUSION}

\author{
Gleyce Carvalho CASTRO (UFPA) ${ }^{1}$
}

Resumo: O presente trabalho tem como objetivo analisar os desafios da pandemia em relação a efetivação da inclusão de crianças com necessidades educativas especiais. A importância de discutir este tema se justifica pela necessidade de compreensão da forma como o sistema educacional vem trabalhando o processo de garantia de direitos nesse momento de pandemia. Para a realização dessa abordagem utilizou-se como proposta metodológica a pesquisa qualitativa e pesquisa de bibliografias em documentos, parecer, artigos e livros de autores como Mantoan (2015), Lima (2016), Hansel, Zych, Godoy (2014), dentre outros. A pesquisa mostra insuficiência na eficácia com que as políticas educacionais estão sendo veladas nesse momento de pandemia, aponta para problemas já existentes na educação e que com o momento que estamos vivenciando tem só se intensificado. A inclusão é um processo que deve ser encarado com responsabilidade, criando possibilidades para que ocorra de forma satisfatória.

Palavras Chave: Aprendizagem. Inclusão. Pandemia.

\begin{abstract}
This paper aims to analyze the challenges of the pandemic in relation to the effective inclusion of children with special educational needs. The importance of discussing this topic is justified by the need to understand how the educational system has been working the process of guaranteeing rights at this time of pandemic. For the realization of this approach used as methodological proposal the qualitative research and bibliographic research in documents, opinion, articles and books of authors such as Mantoan (2015), Lima (2016), Hansel, Zych, Godoy (2014), among others. The research shows insufficiency in the effectiveness with which educational policies are being veiled at this time of pandemic, points to already existing problems in education and that with the moment we are experiencing has only intensified. Inclusion is a process that must be faced with responsibility, creating possibilities for it to occur in a satisfactory manner.
\end{abstract}

Keywords: Learning. Inclusion. Pandemic.

\footnotetext{
${ }^{1}$ Mestranda do Programa de Pós-graduação em Cidades, Territórios e Identidades/PPGCITI pela Universidade Federal do Pará (UFPA). Possui graduação em Pedagogia pela Faculdade de Educação e Tecnologia da Amazônia (FAM, 2020) e graduação em Educação do Campo pela Universidade Federal do Pará (UFPA, 2018). E-mail: gleycecarvalho39@gmail.com
} 


\section{INTRODUÇÃO}

O cenário brasileiro perpassa por momentos obscuros em todos os aspectos e que são imensuráveis, a pandemia causada pela COVID19 modificou totalmente a vida cidadã, afetou diretamente a saúde e respectivamente a vida social, cultural, educacional, dentre outras áreas. As escolas tiveram que fechar as portas e se reinventar na busca de metodologias para que o ensino não fosse prejudicado.

Os estados e municípios brasileiros adotaram medidas emergenciais articulados com as instituições buscando formas de ensino que contemplassem a realidade de cada região, conforme as necessidades dos alunos e suas condições de acesso a esse ensino. O EAD (ensino a distância) foi adotado por algumas instituições, mas o acesso à internet não é realidade de todos.

A educação é direito de todos, incluindo dos alunos com necessidades educacionais especiais, incluí-los no sistema público de ensino é também uma forma de respeitar e garantir a possibilidade de desenvolvimento de suas potencialidades. Borges (2005, p.3, apud BORTOLOZZO 2007, p. 15) afirma que, "um aluno tem necessidades educacionais especiais quando apresenta dificuldades maiores que os restantes dos alunos da sua idade para aprender o que está sendo previsto no currículo, precisando assim, de caminhos alternativos para alcançar este aprendizado".

Para que a inclusão aconteça é necessário que o Estado, a família e a escola estejam em sintonia, pois, a ideia de inclusão é mais do que somente garantir o acesso a entrada de alunos nas escolas, o objetivo é eliminar obstáculos que limitam a aprendizagem e a participação do aluno no processo educativo.

Este trabalho tem como objetivo analisar os desafios da pandemia em relação a efetivação da inclusão de crianças com necessidades educativas especiais. A inclusão é um processo que deve ser encarado com responsabilidade, criando possibilidades para que ocorra de forma satisfatória. De que forma o sistema educacional vem trabalhando esse processo de garantia de direitos nesse momento de pandemia? Essa pergunta justifica a temática deste trabalho.

O direito à educação inclusiva é garantido tanto pela Constituição, quanto pela convenção sobre os direitos da Pessoa com Deficiência da ONU, e a Lei Brasileira de Inclusão (LBI), de ${ }^{\circ}$. 13.146/2015. Em relação ao contexto específico da pandemia, consta no parecer $\mathrm{n}^{\mathrm{o}}$. 5 do CNE a necessidade a esse direito, garantindo a qualidade e equidade.

Para a realização dessa temática, utilizou-se a pesquisa bibliográfica em documentos, parecer, artigos e livros de autores que darão embasamento teórico para este trabalho, e a pesquisa qualitativa. 
Para Rampazzo (1998), “a pesquisa bibliográfica faz parte de qualquer pesquisa, em qualquer área; supõe e exige o levantamento da situação em questão a partir de uma fundamentação teórica".

A pesquisa qualitativa ou naturalística, segundo Bodgan(Bogdan) e Biklen (1982), “envolve a obtenção de dados descritivos, obtidos no contato direto do pesquisador com a situação estudada, enfatiza mais o processo do que o produto e se preocupa em retratar a perspectiva dos participantes". (LÜDKE; ANDRÉ, 1986, p. 13). Esse tipo de pesquisa valoriza o ser humano.

A pesquisa mostra que o momento é de desafios para todos, onde a escola, os professores, pais e alunos têm papéis cruciais na concretização do ensino, para que ele aconteça de forma satisfatória deve ser encarado com responsabilidade por todos. No entanto, as medidas emergenciais se mostram insuficientes em assegurar a qualidade do ensino inclusivo.

\section{EDUCAÇÃO INCLUSIVA: DO QUE ESTAMOS FALANDO?}

Para que alcançasse as bases da educação inclusiva foram muitos os processos sofridos ao longo do tempo pelas pessoas com deficiência, que vão desde a exclusão, segregação até as práticas mínimas de inclusão. Discussões sobre um sistema de ensino inclusivo, passou a ser encarado como prática necessária para a oferta e efetivação de um ensino de qualidade.

O direito à educação é garantido por lei, com uma educação de qualidade para todos, implica, dentre outros fatores, num redimensionamento de todo o contexto escolar, considerando não somente a matrícula, mas, principalmente, a valorização das aptidões e respeito às diferenças. Assim, o resgate dos valores culturais, que fortalecem a identidade e o coletivo populacional, propõe preparar para o enfrentamento de desafio com a oferta da educação inclusiva e de qualidade para todos, sendo respeitadas as características próprias de interesses e ritmos de aprendizagem. Desafio que a escola por seu histórico de homogeneidade e segregação mantido, até então, não está apta para lidar com a diversidade (HANSEL, ZYCH, GODOY, 2014, p.14).

A educação sendo direito de todos, e para que todos fossem contemplados por ela e fossem participantes do processo de ensino e aprendizagem sem exceções, é que surge a chamada Educação Inclusiva. Para que ocorresse a chamada Educação Inclusiva faz-se necessário compreender o motivo dela surgir, assim como a necessidade e importância de ela existir, para isso as pessoas com deficiências ou tidas como diferentes dos padrões sociais, pudessem estar nos espaços escolares eles sofreram exclusão da sociedade. Para Mantoan: 
A exclusão escolar manifesta-se das mais diversas e perversas maneiras, e quase sempre o que está em jogo é a ignorância do aluno diante dos padrões de cientificidade do saber escolar. Ocorre que a escola se democratizou abrindo-se a novos grupos sociais, mas não aos novos conhecimentos. Exclui, então, os que ignoram o conhecimento que ela valoriza e, assim, entende que a democratização é massificação de ensino e não cria a possibilidade de diálogo entre diferentes lugares epistemológicos, não se abre a novos conhecimentos que não couberam, até então dela (MANTOAN, 2003, p.13).

Quanto à inclusão, Mantoan questiona não somente as políticas e a organização da educação especial no ensino regular, mas também o próprio conceito de integração. Ela é incompatível com a integração, pois prevê a inserção escolar de forma radical, completa e sistemática. Todos os alunos, sem exceção, devem frequentar as salas de aula do ensino regular.

A educação inclusiva deve ser entendida como uma tentativa a mais de atender às dificuldades de aprendizagem de qualquer aluno no sistema educacional e com um meio de assegurar que os alunos, que apresentam os mesmos direitos que os outros, ou seja, os mesmos direitos dos seus colegas escolarizados em uma escola regular. (Mantoan, 2003, p. 37).

A educação inclusiva envolve todos os grupos sociais, onde o essencial não foca apenas na democratização do ensino, e sim na concretização do que está pautado na constituição, onde todos têm os mesmos direitos de serem escolarizados e assim que necessário receberem atendimento educacional especializado.

Com base em Lima

A inclusão, portanto, não é algo que se fala, mas algo que se vive, intensa e conscientemente, contínua e tenazmente, concreta e francamente. A inclusão é a participação de todos pelo todo, com todos. A inclusão não é uma mera teoria da moda, mas uma atitude de vida; uma expressão de sociedade e cidadania; uma compreensão de que todos os seres humanos são humanos sem distinção. (LIMA, 2006, p. 63),

Entende-se que a Educação Inclusiva é o atual paradigma da educação brasileira, o qual exige que as escolas se transformem para que todos os alunos possam ter acesso, permanência e sucesso em seu contexto, constituindo-se em um processo de mudanças em todos os aspectos da instituição escolar, para que esta acolha todos os alunos, respeitando suas diferenças, necessidades e valorizando as suas potencialidades.

\section{DESAFIOS PARA A INCLUSÃO}


Para que a inclusão se efetive nos espaços escolares existem desafios a serem encarados e estereótipos a serem quebrados que são criados até mesmo no interior das instituições.

Para Mantoan:

Os problemas conceituais, desrespeito a preceitos constitucionais, interpretações tendenciosas de nossa legislação educacional e preconceitos distorcem o sentido da inclusão escolar, reduzindo unicamente à inserção de alunos com deficiência no ensino regular (MANTOAN, 2003, p.22).

A autora faz referência a inclusão e a inserção, é necessário refletir sobre o papel que a escola está assumindo diante de alunos com deficiência, será que a escolarização está acontecendo com base nos direitos previstos na constituição, ou a escola está assumindo somente papel assistencial. Um aluno com deficiência matriculado na escola de ensino regular juntamente com seus colegas não é inclusão, ele apenas está inserido no espaço escolar, o que irá determinar a inclusão são as práticas das escolas diante da necessidade desse aluno, se ela de fato está contribuindo para o desenvolvimento de suas potencialidades cognitivas, sociais, afetivas e motora.

No processo de escolarização a criança que apresenta necessidades educativas especiais, precisa de uma atenção especial para que possa acompanhar os seus colegas no processo de ensino, através de propostas de ensino que viabilize esse aprendizado. $\mathrm{O}$ aluno que possui dificuldades educacionais especiais, não necessariamente tem algum tipo de deficiência pode ser que seja apenas um atraso na sua aprendizagem, mas é preciso se pensar em metodologias que possibilite um desencadear de possibilidades visando o seu desenvolvimento.

A inclusão está sendo bastante discutida na atualidade, e parte do pressuposto da igualdade, mas nem todos somos iguais e tratar com igualdade os diferentes já é exclusão, dentro dos processos formativos, cada sujeito deve ser pensado de acordo com suas reais necessidades, mas isso não é tarefa fácil, e por isso acaba sendo deixada em segundo plano.

Os desafios para a inclusão são postos desde o convívio familiar até o convívio social, a partir do momento em que a criança com deficiência com costumes e crenças diferentes, com modo de se vestir e se comportar que não são considerados normais passam a ser percebidos por essa nossa sociedade classista e preconceituosa. Diante disso, a pessoa passa a não se aceitar, e se isola da sociedade que deveria acolher.

São inúmeros prejuízos causados na vida do indivíduo, que se manter afastado e sozinho é considerado a solução. E quando esse indivíduo passa a frequentar os espaços escolares, é papel da 
escola identificar os comportamentos que dificultam a interação do aluno, e assim trabalhar no seu dia a dia formas de incluí-lo no meio social, que vão de uma roda de conversa e brincadeiras à uma tomada de decisão independente. Isso acontece em espaços escolares com bases sólidas, ancorados por práticas inclusivas e com comprometimento em efetivar a chamada educação para todos.

No entanto, os desafios para a inclusão não são apenas escolares, o preconceito apresenta diversas facetas que estão presentes no grupo familiar, nos hospitais, no supermercado, na vizinhança, e que estão longe de serem extinguidos, cada vez mais estão surgindo com novos rótulos, com novos atores em uma doce ironia que acaba destruindo com a vida de quem sofre com qualquer tipo mínimo de exclusão.

Pensar em inclusão, não é brincar de "faz de conta", faz de conta que eu te respeito e você faz de conta que está sendo respeitado. É fazer a diferença nas ações, é rever os comportamentos, as atitudes, os tipos de risos e se colocar no lugar do outro para saber até que ponto quem está ao meu lado se sente com minhas ações. Assim, o respeito vai se consolidando e práticas mínimas de inclusão vão se constituindo.

A pandemia vem aflorar as desigualdades sociais que nesse momento tem se intensificado, o que se torna desafiador para todos os participantes do processo educativo, a escola enquanto instituição, professores, pais e alunos têm papéis essenciais para a continuidade do ensino, esses atores estão ressignificando o fazer educativo.

O papel da escola é acolher e oferecer maneiras para que esse aluno alcance seus objetivos educacionais. A Lei $\mathrm{n}^{\mathbf{0}} 7.853 / 89$, de 1989, dispõe sobre o apoio às pessoas portadoras de deficiência e sua integração social, define como crime recusar, suspender, adiar, cancelar ou extinguir a matrícula de um estudante por causa de sua deficiência, em qualquer curso ou nível de ensino, seja ele público ou privado. A pena para o infrator pode variar de um a quatro anos de prisão mais multa.

O papel do professor é um muito importante nesse processo, pois precisa de dedicação e comprometimento com a educação, criar, recriar metodologias que proporcione ao aluno com necessidades educacionais especiais o desenvolvimento de suas potencialidades, que motive e desperte o interesse da criança, não é uma tarefa fácil, mas é necessária quando se pensa na inclusão.

De acordo com Luckesi:

Um educador, que se preocupe com que a sua prática educacional esteja voltada para a transformação, não poderá agir inconsciente e irrefletidamente. Cada passo de sua ação deverá estar marcado por uma decisão clara e explícita do que está fazendo e para onde possivelmente está encaminhando os resultados de sua ação. A avaliação neste contexto, não poderá ser uma ação mecânica. Ao contrário, terá que ser uma 
atividade racionalmente definida, dentro de um encaminhamento político e decisório a favor da competência de todos para a participação democrática da vida social (LUCKESI, 2005, p. 46).

O professor deve buscar metodologias que contemple a todos os alunos sem exceções, é uma grande responsabilidade na realidade educacional dos alunos, a prática pedagógica é que vai determinar o fazer educativo, se é inclusivo ou excludente, pois dentro do processo de ensino inclusivo, a prática pedagógica e o modelo de ensino a ser ofertado é determinante na escolarização do aluno com necessidades educacionais especiais.

O sistema educacional teve que se reinventar e para os alunos gerou estranheza pois tiveram que se adequar a uma nova rotina a qual lhes foi imposta, assim como o planejamento dos professores ficou diferente, onde a criatividade e flexibilização estão em jogo. A família/escola têm papéis fundamentais para que o ensino seja alcançado, a inclusão depende do empenho e comprometimento de todos.

\section{INCLUSÃO E PANDEMIA}

A inclusão não deve ser apenas discursiva e se fazer presente apenas nos trabalhos acadêmicos ou nas produções de autores renomados, verificamos os rumos da inclusão em nosso país quando atravessamos momentos difíceis, quando verificamos a forma com que as classes sociais estão sendo tratadas e quais as políticas públicas voltadas para atender os direitos básicos de todos. Ter acesso aos direitos elementares, como moradia, saúde, alimentação, educação se tornam difíceis a classe mais pobre, poucos dispõe do mínimo que é oferecido.

Uma escola inclusiva se faz na acessibilidade a todos os alunos, e principalmente nas práticas pedagógicas a qual a escola adota. A inclusão na pandemia é pensar em todas as realidades educacionais, é pensar em metodologias que atenda todos os alunos. Contudo, como menciona SaponShevin:

A criação de uma escola inclusiva onde todos os alunos sintam-se reconhecidos, valorizados e respeitados envolve cuidar dos conteúdos ensinados e da maneira como o currículo é transmitido. Não somente as estratégias de ensino devem ser designadas e as áreas curriculares determinadas para responder a uma ampla variedade de diferenças entre os alunos, mas o próprio currículo deve designar-se às muitas maneiras em que os alunos se diferenciam (SAPON-SHEVIN, 1999, p.288). 
A escola como um espaço de formação humana, deve promover entre todos o respeito às diferenças, deve ensinar que todos somos diferentes, mas que isso não nos torna desigual a ninguém. A escola tem como papel formar pessoas para a cidadania, assim como romper com a cultura do preconceito dentro e fora dos espaços escolares, pois antes mesmo do preconceito ocorrer na sociedade, ele acaba ocorrendo dentro das escolas. Então a escola deve romper com esse silenciamento e através de suas práticas pedagógicas incluir todos.

Nesse momento de pandemia o aluno com necessidades educacionais especiais não pode ser esquecido, ele possui objetivos educacionais a serem alcançados iguais aos outros alunos, tendo direitos assegurados pela constituição, direito a uma atividade diferenciada ainda que em sua casa, essas metodologias devem atender as suas necessidades, as atividades não podem ser únicas para todos, pois alguns aprendem de forma diferenciada, e é dessa maneira que o planejamento deve acontecer. Segundo os Fundamentos da Educação Inclusiva:

Estas adequações e apoios devem ocorrer através de flexibilizações e adaptações dos recursos instrucionais (equipamentos, material pedagógico), capacitação de recursos humanos (instrutores, profissionais especializados, ...), eliminação de barreiras atitudinais, arquitetônicas, curriculares, de comunicação, sinalização, encaminhamento para o mundo do trabalho e acompanhamento dos egressos (HANSEL, ZYCH, GODOY, 2014, p.69).

Mesmo enfrentando uma fase tão delicada, a educação deve ser pensada na eliminação de barreiras que impeçam o aluno na apropriação do conhecimento. $\mathrm{O}$ ensino nas escolas regulares, foi pensado na instrumentalização do ensino, nas metodologias que seriam adotadas para alcance dos alunos, para que todos tivessem acesso à educação, no entanto, com o ensino a distância, é necessário reformular ou adaptar o currículo para que se torne um instrumento de emancipação social. Com base no exposto, os Fundamentos da Educação Inclusiva, trata que:

As adaptações curriculares apoiam-se em pressupostos pedagógicos para melhor poder atender às necessidades educacionais dos alunos, respeitando suas características em geral e suas especificidades em particular. A escolha de um método mais acessível à aprendizagem da criança, a utilização de um texto ilustrado, introduzindo atividades complementares para reforçar, apoiar e/ou ativar o processo educativo, de modo a facilitar a apropriação do conhecimento, faz-se necessário para orientar a tomada de decisão do aluno (HANSEL, ZYCH, GODOY, 2014, p.77).

A aprendizagem deve acontecer da maneira na qual o aluno consiga realizar as atividades, e a realização das atividades dependerá das metodologias adotadas na elaboração das mesmas, os 
Fundamentos da Educação Inclusiva citado acima ressalta sobre a escolha de métodos mais acessível à aprendizagem da criança, métodos que facilitarão o alcance dos objetivos educacionais e que subsidiarão o aluno na sua própria independência.

O papel do professor é um muito importante nesse processo, pois precisa de dedicação e comprometimento com a educação, criar, recriar metodologias que proporcione ao aluno com necessidades educativas especiais o desenvolvimento de suas potencialidades, que motive e desperte o interesse da criança, não é uma tarefa fácil, mas é necessária quando se pensa na inclusão.

Dentro do processo de ensino inclusivo, a prática pedagógica e o modelo de ensino a ser ofertado é determinante na escolarização do aluno com qualquer tipo de deficiência. Alguns alunos irão precisar apenas de auxílios nas atividades outros de total apoio, as adaptações nos conteúdos deverão acontecer de acordo com a necessidade de cada aluno e quando necessárias, são adaptações que não podem ser desiguais dos conteúdos ofertados no currículo, deve seguir os parâmetros curriculares para que esse aluno acompanhe sua turma.

\section{OS BENEFÍCIOS DA INCLUSÃO NA PRÁTICA SOCIAL}

Os benefícios da inclusão não são apenas para a escola, mas para toda a sociedade. Quando a escola está pautada nas práticas inclusivas, isso reflete além de seus muros, vai além do conhecimento contextualizado na sala de aula, vai além da relação entre professor/aluno, diz respeito a valorização do aluno enquanto sujeito de direito, na reafirmação de sua identidade e no próprio discurso adotado pela escola. De acordo com os Fundamentos da Educação inclusiva:

Os valores éticos e políticos que fundamentam a educação inclusiva concorrem efetivamente para a ressignificação do projeto educativo, no sentido de revitalizar as características humanizadoras da proposta cultural com assertivas ações. Conviver na diversidade torna-se uma exigência fundamental a fim de capacitar os cidadãos e toda a sociedade a intervir, com o necessário discernimento, na práxis das relações (HANSEL, ZYCH, GODOY, 2014, p.84).

As ações desenvolvidas pela escola se tornam assertivas quando o aluno se sente incluindo no processo de ensino, quando existe interação entre os diferentes conhecimentos e ocorre a reflexão da práxis educativa. A inclusão acontece no acolhimento ao aluno na sua entrada nas escolas regulares e deverá ser visto como um desafio a ser encarado pelos professores e por toda a comunidade escolar, visando a construção de um sistema educacional estruturado baseado nos paradigmas inclusivos. 
O aluno que consegue desenvolver suas habilidades por meio da ação docente e das práticas pedagógicas desenvolvidas pela escola, seja o aluno com necessidades educativas especiais ou não, faz com que aconteça com eficiência a inclusão escolar e também a inclusão social. É a compreensão do papel bem elaborado da escola em incluir esse aluno em todas as esferas da sociedade, o que começa no acolhimento e matrícula desse aluno nas escolas de ensino regular até o seu pleno desempenho por toda a sua existência.

A inclusão social, (...), é um processo que contribui para a construção de novo tipo de sociedade através de transformações, pequenas e grandes, nos ambientes físico a (espaços internos e externos), equipamentos, aparelhos e utensílios, mobiliário e meios de transporte) e na mentalidade de todas as pessoas, portanto também do próprio portador de necessidades especiais (SASSAKI, 1999, p.42).

Relações vivenciadas na escola se tornam harmoniosas no convívio entre os diferentes, onde os que não possuem deficiência passam a respeitar os que possuem a partir de conceitos considerados errôneos pelos "normais", essa convivência é essencial para alunos tornando-os mais tolerantes e compreensíveis pois, passam a conhecer uma outra realidade, que antes desconheciam.

A escola passa por novas rotinas e experiências quando estão intrinsecamente ligados na diversificação do planejamento escolar, os professores se tornam mais capacitados quando encaram o desafio com responsabilidade, acompanhando as transformações e inovações que rodeiam a sua área profissional, tornando-os melhores profissionais. A relação entre família/escola acontece com êxito quando articulados entre si, quando se dispõe a adaptar o currículo com a participação democrática, criando oportunidades iguais de aprendizagem para todos os alunos.

A inclusão é um processo que contribui para a construção de uma sociedade melhor, com respeito às diferenças, criando ambientes inclusivos, a partir de apoio educacionais adequados, rompendo com as práticas segregacionistas e com os ambientes excludentes. Os benefícios da inclusão estão na oportunidade de as pessoas aprenderem umas com as outras, respeitando o que é diferente e criando laços que pouco a pouco vão desmistificando conceitos criados por uma sociedade excludente e promovendo a justiça social.

\section{RESULTADOS E DISCUSSÕES}


O trabalho mostra que a inclusão escolar é um processo que não depende unicamente do professor ou somente da escola, depende necessariamente da construção de um sistema público consistente e articulado com um projeto político e educacional, que contemple uma formação humanizadora e seja eficiente para todos os alunos.

Quando Vygotsky (1997) argumenta que os objetivos educacionais em relação às crianças com deficiência precisam ser os mesmos para as crianças tidas como normais, ele se ancora nas leis gerais do desenvolvimento cultural. Não se trata, portanto, de reduzir as expectativas em relação ao processo de ensino e aprendizagem, tampouco, de ignorar a deficiência, admitindo que todos podem aprender tudo ou qualquer coisa em determinado tempo ou momento, desconsiderando as condições e a história de cada pessoa.

Outra questão para se analisar é o despreparo das escolas diante da inclusão, a prática pedagógica é determinante para sua efetivação, o professor deve buscar formações com o intuito de renovar seus saberes e aprimorar sua prática.

Com isso a formação continuada é crucial na busca do conhecimento, o professor que almeja inovação, e atualizações diante do contexto educacional, busca ainda que com seus próprios recursos por essa formação, o sistema educacional, poucas vezes ou nenhuma, discute práticas inclusivas e/ou metodologias voltadas para a inclusão escolar, as discussões devem surgir a partir das problemáticas existentes no dia a dia escolar com o intuito de buscar melhorias para o romper com paradigmas excludentes que ainda persistem na sociedade. Diante disso, os fundamentos da educação inclusiva ressaltam que:

O professor como líder precisa estar atento para a convivência em classe, cuidando para que ele não se torne apenas mais um na sala. Todo aluno precisa sentir-se acolhido e respeitado para assumir seu espaço com segurança e desenvolver sua autoestima, com estímulo a introduzir-se no movimento do cotidiano escolar sendo beneficiado com o processo inclusivo (HANSEL, ZYCH, GODOY, 2014, p.28).

O papel da escola é não tornar o diferente em excluído, é de atender todos os alunos, estar matriculado e frequentando as escolas de ensino regular é um direito de todos, no entanto a escola deve criar possibilidades para que esses alunos desenvolvam suas habilidades cognitivas, afetivas e motoras. Ainda no momento o qual estamos passando, deverá acontecer o planejamento da equipe escolar, e nesse "planejar" deverá se pensar em todos, a própria escola deverá criar o ensino inclusivo ao invés de barreiras que limitem a qualidade desse ensino. 
O respeito aos traços característicos que fundamentam a cultura de tão numerosas civilizações que povoam o nosso país, torna-se altamente significativo. Considerando a função da escola, que tem como objetivo forte dar oportunidade para que as pessoas desenvolvam o próprio potencial e transformem-se em cidadãos vencedores, dos medos, dos traumas, das lutas e dos desafios que a vida lhes impõe (HANSEL, ZYCH, GODOY 2014, p.93).

Os pais devem participar ativamente da educação dos filhos, ainda que tenham limitações para ensiná-los, é responsabilidade dos pais compreender o processo educativo do seu filho, isso realça o seu compromisso com o seu desenvolvimento, quando a criança percebe que todos estão empenhados em contribuir na sua formação, isso desperta o seu interesse em aprender. Portanto, a inclusão é responsabilidade de todos e jamais poderá ser atribuída unicamente a uma pessoa, deverá ser pensado sempre no coletivo.

A interação com a família representa um ganho de fundamental importância em todas as situações e, quando se trata do aluno com necessidades educacionais especiais, os vínculos que se estabelecem tornam-se fundamentais na superação dos conflitos, acima de muitos outros recursos. Pela riqueza de informações, a parceria com a família ou atendentes poderá auxiliar, desmistificando comportamentos inadequados. Esta é uma via capaz de oferecer maior validade às intervenções escolares levando o aluno a compartilhar, interagir e projetar suas ideias (HANSEL, ZYCH, GODOY, 2014, p.15).

O currículo deverá ser adaptado conforme as necessidades apresentadas pelos alunos e não o aluno se adaptar aos padrões impostos pelas instituições. A flexibilização do currículo envolvendo os alunos que necessitam de apoio educacional na realização das atividades deverá acontecer quando identificadas as dificuldades de aprendizagem dos alunos e assim considerada uma importante ferramenta pedagógica, o mesmo currículo deverá contemplar todos os sujeitos que por direito requerem a educação e que seja ofertada de forma qualitativa.

A democratização da escolarização pautada nas perspectivas do ensino inclusivo parte do pressuposto de que todos têm direito a educação e de aprender do seu modo e a partir de sua própria compreensão, só que para que esses objetivos sejam alcançados o aluno deve dispor de um currículo que envolva esses objetivos e que contenha as adaptações necessárias para o seu desenvolvimento.

O desafio imposto à escola e aos professores de promover a socialização de alunos com necessidades educativas especiais é grande, e uma parte significativa continua "não preparada" para desenvolver estratégias de um ensino diversificado. Com todas essas dificuldades os alunos com necessidades educacionais especiais continuam matriculados na escola, pois estar na escola é direito, 
mas somente isso não basta, é necessário que a escola exerça seu papel em oferecer uma educação a todos e crie metodologias para uma inclusão possível.

As medidas emergenciais adotadas pelo sistema educacional de alguma forma acabam contribuindo para o aumento das desigualdades e negação do direito das crianças e adolescentes com necessidades educativas especiais. Concordando com o que diz nos Fundamentos da Educação Inclusiva que,

Constata-se desta forma, que importantes iniciativas foram consolidadas, porém, muito ainda há que se fazer para que a inclusão efetive seus níveis idealizados. Com certeza, a acessibilidade constitui-se no instrumento concreto, capaz de mediar o processo de inclusão, porém, como as leis tornam-se insuficientes para garantir a realização da proposta inclusiva há que se realizar um esforço em conjunto com a comunidade escolar para que haja o acesso e a permanência para todos os educandos, indistintamente (HANSEL, ZYCH, GODOY, 2014, p.16).

Portanto, as políticas públicas que estão sendo conduzidas nesse momento de pandemia, se mostram insuficientes na eficácia de atender os sujeitos educacionais para que a educação seja de fato inclusiva.

\section{CONSIDERAÇÕES FINAIS}

O trabalho mostra a importância da inclusão escolar e as dificuldades que o sistema educacional ainda enfrenta na efetivação desse ensino, são questões que necessitam ser discutidas de modo que haja avanços na criação ou reformulação de políticas voltadas para a inclusão.

A inclusão vem sendo discutida a algum tempo em diversos espaços físicos que perpassam o ambiente escolar, abrangendo os diversos grupos sociais existentes na sociedade. Neste trabalho foi discutido a inclusão escolar em tempos de pandemia, em tempos de uma crise que está modificando a vida de todos em diferentes aspectos, se adequar a uma nova rotina assusta, é desafiador, mas é o "novo normal".

O processo de inclusão tem avançado e agora não é momento de retroceder, é momento de continuar firme, reafirmando o compromisso em assegurar o direito de todos. O direito a educação é de todos, mas olhar com igualdade para todos pode ser um processo excludente, pois não somos iguais, não apresentamos os mesmos comportamentos, alguns apresentam dificuldades de aprendizagem mas não são deficientes, outros possuem deficiência mas que não limitam a sua aprendizagem, são sujeitos educacionais em diferentes níveis que apresentam especificidades 
próprias, que assim como os que não tem dificuldades de aprendizagem, precisam ser escolarizados, ainda que com a flexibilização dos conteúdos curriculares.

Experenciamos tempos difíceis que requer postura sólida diante das situações postas como desafios, no entanto nem todos tem estrutura psíquica ou emocional nesse momento, com os professores, gestores, pais e alunos não é diferente cada um está enfrentando essa crise da sua maneira para que a educação continue sendo possível.

As escolas estão se reinventando, os professores superando seus próprios limites e os alunos e os pais estão tendo que adaptar a essa nova realidade, pois os pais mais que nunca tem papel crucial na educação dos filhos, não é tarefa fácil, enfrentar a crise e dar continuidade ao ensino, respondendo as necessidades de cada aluno, mas em nenhum momento isso foi tarefa fácil, se manter firme com o objetivo de atender todos de forma satisfatória são práticas inclusivas.

A pesquisa aponta para problemas já existentes na educação e que com o momento com o qual estamos vivenciando tem só se intensificado. Quando falamos em inclusão escolar, falamos em metodologias que contemplem todos os alunos, envolvendo aspectos sociais, econômicos, raciais e psicológicos.

O momento é desafiador, as atividades pedagógicas neste momento exigem um pouco mais de elaboração, a criatividade e flexibilidade dos professores são postas a prova para que consigam articular atividades para esses alunos. Nem todo aluno escuta, fala, enxerga, se locomove, mas esse aluno também tem objetivos educacionais a serem alcançados, mas para isso precisa-se de planejamento e dedicação de todos os envolvidos no processo educacional.

A família é a ponte entre a escola e o aluno, pois será a família que auxiliará o aluno a desenvolver as atividades de modo presencial. Sendo assim, a informação através de conversas entre docentes e pais, darão subsídios para haja compreensão sobre os objetivos que deverão ser alcançados com as atividades que são enviadas para os alunos, para que não haja desentendimento, é o momento em que a participação dos pais se tornou essencial.

A escola através de projetos inclusivos deverá criar possibilidades de inclusão e que nesse momento a relação família/escola é imprescindível. As atividades não devem ser feitas de qualquer forma, é necessário elaboração de metodologias que atenda as especificidades do aluno, a escola não deve fazer a família pensar que o aluno não consegue compreender as atividades, pois se isso acontece a família não verá o porquê da permanência desse aluno na escola e o projeto de inclusão que visa o convívio do aluno com deficiência nas classes de ensino regular não terá significado. 
A educação é muito mais que ensinar a ler, a escrever e a realizar cálculos matemáticos, forma cidadãos críticos para uma vida pública e que saibam lidar com os obstáculos e possibilidades que possam surgir ao longo da vida. O papel da escola é criar possibilidades para que esses objetivos sejam alcançados, se reinventando, criando e oferecendo subsídios de aprendizagem para todos os alunos, pois são desafios do fazer pedagógico. A família deve ter a escola como um direito, um ambiente em que os alunos irão aprender a socializar e desenvolver suas habilidades para direcionamentos de uma vida futura.

O papel da escola e do professor são fundamentais no processo de inclusão, é preciso romper com padrões preconceituosos e que a inclusão seja efetivada a partir de práticas e ações pedagógicas inclusivas.

Portanto, todos têm condições de aprender sim, alguns com modos de aprender diferentes em relação aos demais, o planejamento, a flexibilização, o comprometimento e a prática pedagógica são fundamentais para que os objetivos educacionais sejam alcançados, assim como políticas de valorização docente, formação continuada e políticas de inclusão são essenciais para a efetivação do ensino inclusivo nos espaços escolares.

\section{REFERÊNCIAS}

BORTOLOZZO, Ana Rita Serenato. Banco de dados para o uso das tecnologias de informação e comunicação na prática pedagógica de professores de alunos com necessidades especiais. Dissertação de Mestrado. Pontifícia Universidade Católica do Paraná, 2007.

Diretrizes curriculares da educação especial para a construção de currículos inclusivos. Secretaria de Estado da Educação - SEED. - Curitiba, 2006.

HANSEL, Ana Flávia; ZYCH, Anizia Costa e GODOY, Mirian Adalgisa Bedim. Fundamentos da Educação Inclusiva. Gráfica Unicentro. Paraná, 2014.

LÜDKE, Menga; ANDRÉ, Marli E. D. A. Pesquisa em Educação: abordagens qualitativas. São Paulo: EPU, 1986.

LUCKESI, C. C. Avaliação da aprendizagem escolar: estudos e proposições. São Paulo: Cortez, 2005.

LIMA, Francisco José de. Ética e inclusão: o status da diferença. In: MARTINS, Lúcia de Araújo Ramos; PIRES, José; PIRES, Gláucia Nascimento da Luz; MELO, Francisco Ricardo Lins Vieira de (ORG.). Inclusão: compartilhando saberes. Petrópolis (RJ): Vozes, 2006.

MANTOAN, M. T. E. A hora e a vez da Educação Inclusiva. Revista Educação e Família, edição 05, ano I, p. 42-45, 2005a. 
. A integração de pessoas com deficiência: Contribuições para uma reflexão sobre o tema. São Paulo: Memnon, 1997.

Inclusão escolar: o que é? Por quê? Como fazer? São Paulo, ed. Moderna, 2003. (Coleção cotidiano escolar)

RAMPAZZO, L. Metodologia científica: para alunos de graduação e pós-graduação. Lorena: Stiliano, 1998. P.55-56.

SAPON-SHEVIN, Mara. Celebrando a Diversidade, Criando a Comunidade: O Currículo que Honra as Diferenças, Baseando-se Nelas. In: STAINBACK, Susan; STAINBACK, Willian. Inclusão: um guia para educadores. Trad. Magda França Lopes. Porto Alegre: Artes Médicas, 1999.

SASSAKI. R.K. Inclusão: construindo uma sociedade para todos. Rio de Janeiro: WVA, 1999.

VYGOTSKI, Lev Semyonovich. Obras escogidas, v. V. Madrid: Visor, 1997. 